\title{
A língua de Odisseu e a boca de Polifemo: o selvagem- político no Ciclope de Eurípides
}

\author{
Mateus Dagios ${ }^{1}$
}

— Devorá-los! — foi a resposta do truculento canibal. ${ }^{2}$

\begin{abstract}
Resumo: O texto é uma análise da ideia de selvagem no Ciclope de Eurípides. O conceito de selvagem agrupa para o pensamento grego uma série de referências negativas que contrastam com o ideal grego de cidadão. $\mathrm{O}$ discurso do selvagem é compreendido como uma "ideologia do selvagem", que organiza os referenciais identitários da pólis, sendo central na discussão da alteridade e das fronteiras. $\mathrm{O}$ artigo discute como o mito de Polifemo é reestruturado por Eurípides, mantendo o embate entre Ciclope e Odisseu, mas desenvolvendo elementos de barbárie e selvageria em um contexto político relativo à Atenas do século $\mathrm{V}$ a.C.
\end{abstract}

Palavras-chave: Ciclope; selvagem; Odisseu; Eurípides; política.

\begin{abstract}
This paper aims to analyze the notion of savagery in Euripides' Cyclops. In Greek thought, the notion of savagery comprises several negative characteristics which are contrasted with the ideal Greek citizen. References to savagery make up an "ideology of the savage", essential to the organization of an identity framework for the polis and central to discussions about alterity and borders. This paper discusses how the myth of Polyphemus is restructured by Euripides, who keeps the conflict between Cyclops and Odysseys, but expands barbarianism and savagery into a political context related to fifth-century Athens.
\end{abstract}

Keywords: Cyclops; savagery; Odysseus; Euripides; politics.

Introdução

Talvez o mais famoso encontro da Odisseia ${ }^{3}$ seja o de Odisseu e Polifemo (Odisseia, IX, 106-555). De um lado, o viajante saudoso de sua casa, que desembarca em uma ilha com seus companheiros; de outro, uma criatura selvagem, que despreza todos os rituais cabíveis a um anfitrião e envolve o viajante em um cruel festim canibal. A resolução desse encontro ajudou a construir a fama de Odisseu, o "héroi-métis" que se metamorfoseia em "herói-outis".

Não foram poucos os autores que efetuaram recriações modernas com usos políticos do encontro desses dois tipos distintos. Joyce em seu Ulysses ambientou a cena em uma taverna, e nela a independência da Irlanda é motivo de conversação entre Leopold Bloom e um grosseirão avantajado que ecoa o monstro homérico ${ }^{4}$. Adorno \& Horkheimer (1985)

1 Doutor em História pela Universidade Federal do Rio Grande do Sul (UFRGS).

2 LOBATO (1927).

3 HOMERO (2011).

4 Para uma discussão do Ciclope em Joyce, ver Blamires (1996). 
em Dialética do esclarecimento ${ }^{5}$ interpretaram Odisseu como um herói civilizador que preconiza em seus atos os emblemas da civilização burguesa ocidental, frente a uma criatura que representa um estágio anterior de humanidade, a astúcia mercantil defronte a um caçador-coletor.

De outra forma foi proposta também a reconfiguração desse encontro em literaturas pós-coloniais. Sylvia Wynter (2002), analisando textos de Aimé Césaire e Derek Walcott, chegou a indicar para públicos periféricos uma postura de leitura denominada "a Cyclopean poetics of reading", em que convoca leitores a pensar que o encontro de Odisseu e Ciclope representa a dimensão do encontro colonial. Polifemo definiria uma diferença na criação de imagens entre colonizador e colonizado.

O encontro de Polifemo e de Odisseu permite uma série de reflexões sobre alteridade, selvageria, identidade e construção de noções civilizatórias. Podemos retomar a interrogação de Hartog sobre os Citas em Heródoto: "a questão da alteridade levanta a da fronteira: onde passa a cesura entre o mesmo e o outro?” (HARTOG, 1999, p. 97). Por habitar a fronteira do selvagem, Polifemo possibilita ao viajante uma gama de questões éticas, e as categorias de identidade são colocadas no cerne das reflexões.

$\mathrm{O}$ que propomos é problematizar a perspectiva desse encontro no drama satírico $\mathrm{Ci}$ clope de Eurípides. O texto euripidiano constitui um ponto privilegiado para as questões de identidade e alteridade, além de apresentar o episódio homérico permeado por significados cômicos.

Como é frequente no teatro antigo, há uma discussão em torno da datação do Ciclope, com duas grandes vertentes. Para Seaford (1982), a peça pertence a um momento tardio. Por conta da proximidade linguística entre Ciclope e Orestes (408 a.C.), das semelhanças temáticas com o Filoctetes (409 a.C.) de Sófocles e da inovação de três atores no palco, o texto estaria situado nos últimos anos da Guerra do Peloponeso. De outra forma, Sutton (1980, p. 59) defende que o drama pertence a um período intermediário da vida do autor, possivelmente em torno de 424 a.C., por uma proximidade com a tragédia Hécuba (424 a.C.), sendo similar o papel da cegueira associada à vingança nas duas peças.

Apesar de ter características cênicas particulares, o drama satírico é um gênero de difícil definição porque o único que restou em sua totalidade é o próprio Ciclope de Eurípides. Dos demais, só nos restaram fragmentos ou títulos ${ }^{6}$. Em seu estudo Satyric play: the evolution of Greek comedy and satyr drama, Carl A. Shaw (2014, p. 3) argumenta que, apesar de existirem semelhanças com a tragédia e a comédia, o drama satírico é um gênero único e independente. As similaridades com a comédia são pareadas em níveis de enredo: "ambos os gêneros com frequência concluem com finais felizes e compartilham muitos dos mesmos personagens, enredos, títulos e temas" (ibid., p. 2) ${ }^{7}$. Contudo, do ponto de vista formal, apresenta bastantes similaridades com o texto trágico, sendo que em vários fragmentos é impossível distinguir entre a natureza de um ou outro. A diferença marcante entre tragédia e drama satírico reside na escolha de determinadas abordagens mitológicas:

5 Ver Adorno \& Horkheimer (1985).

6 Para os principais fragmentos de drama satírico, ver O’Sullivan \& Collard (2013).

7 As notas com citações no original indicam traduções nossas. No original: "both genres regularly conclude with happy endings and share many of the same characters, plots, titles, and themes". 
Era quase sempre situado no mundo rústico, primordial e mitológico dos sátiros e explorava proeminentes temas e motivos românticos que eram geralmente evitados na tragédia, como ambientes pastorais, ogros, aventuras e fugas milagrosas, necromancia e ressurreições dos mortos, jantares, simpósios, competições musicais e atléticas e encontros eróticos bem-sucedidos (conhecer-se, apaixonar-se, cortejar) que com frequência terminavam em casamento (SHAW, 2014, p. 83) ${ }^{8}$.

O enredo do Ciclope de Eurípides é construído nas dimensões pastorais do drama satírico, sendo a reescritura do encontro do ogro canibal e do astucioso viajante. A peça é permeada por elementos cômicos, principalmente por Sileno e os Sátiros. De acordo com a divisão aristotélica das partes constitutivas, podemos apresentar a peça da seguinte maneira (KOVACS, 2001):

Prólogo (1-40): Sileno, o companheiro fiel de Dionísio, conta as desventuras causadas pelos serviços que prestou ao deus, tendo sido desterrado com seus filhos, os Sátiros, na ilha aos pés do Etna, onde são escravos do Ciclope Polifemo. Os Sátiros, que compõem o coro da peça, trabalham no pastoreio de ovelhas. A Sileno cabe a função de limpar a caverna do ogro.

Párodo (41-81): entrada festiva do coro, que dança e canta, mas lamenta a condição de abandono.

$1^{\mathrm{o}}$ episódio (82-355): dividido em duas partes. Na primeira (82-202), Sileno avista um navio, que traz uma comitiva de estrangeiros chefiada por Odisseu. Sileno descreve os hábitos selvagens de Polifemo e relata que na ilha os visitantes são devorados. O alegre Sileno recebe vinho de Odisseu e troca por queijos. Os Sátiros pedem informações sobre a Guerra de Troia. Na segunda parte (203-355), Polifemo chega à caverna e quer saber quem são esses homens que comem seus queijos. Acovardado, Sileno inventa que eles o obrigaram a tais atos. Odisseu interrompe a mentira e relata o acordado com Sileno. O Ciclope pede informações sobre o conflito em Troia, e Odisseu reivindica os costumes de hospitalidade. Polifemo ri e ironiza tais leis, explicando que elas não têm relevância em sua caverna e revelando aos viajantes que vai devorá-los.

$1^{\circ}$ estásimo (356-74): os Sátiros imploram que Polifemo não lhes faça participar do festim canibal.

$2^{\circ}$ episódio (375-482): Odisseu sai da caverna, apavorado com os atos de canibalismo que presenciou. Ele revela que o Ciclope adormeceu por causa do vinho e que tem um plano de cegar o selvagem com um tronco incandescente para que possam escapar. Para isso, pede ajuda aos sátiros, que alegres concordam em punir a selvagem figura.

$2^{\circ}$ estásimo (483-518): o coro canta alegres canções. Ao acordar, Polifemo pede mais vinho a Odisseu.

$3^{\circ}$ episódio (519-607): Sileno e Odisseu conversam com Polifemo, que está inebriado. Sileno e o monstro entram na caverna.

Interlúdio coral (608-23): o coro comemora que o selvagem devorador de hóspedes será cegado.

$4^{\circ}$ episódio (624-655): Odisseu sai da caverna e chama os Sátiros para dar prosseguimento ao plano, mas os Sátiros se acovardam.

8 No original: "it was almost always situated in the satyrs' rustic, primordial, mythological world, and it explored prominent romantic themes and motifs that were largely avoided in tragedy, such as pastoral settings, ogres, adventures and miraculous escapes, necromancy and resurrections from the dead, dinners, symposia, musical and athletic competitions, and successful erotic encounters (meetings, falling in love, courtship) often ending in matrimony". 
Interlúdio (656-62): enquanto o coro celebra, Odisseu e seus companheiros cegam Polifemo dentro da caverna.

Êxodo (663-709): cego e cambaleante, Polifemo deixa a caverna. O coro ri de seu estado. Ele diz que procura por Ninguém, que o teria cegado. Ao longe, Odisseu revela seu nome e assume a autoria do ato. Polifemo diz que se cumpriu a profecia que dizia que um homem chamado Odisseu o cegaria. Todos adentram o barco, deixando o Ciclope e celebrando o deus do vinho.

Na própria Antiguidade houve várias reapropriações ${ }^{9}$ do mito no terreno da comédia. Luigi Venezia (2007, p. 96) argumenta que embora tenha havido mudanças sensíveis na história homérica o pano de fundo permaneceu o mesmo: "um monstro cruel e um enganador astuto" $"$.

Na Odisseia (IX, 106-555), a trama entre Odisseu e Polifemo tem duração de dois dias e duas noites. Eurípides reduziu a situação para apenas um dia, diminuindo as três longas refeições canibais de Polifemo para apenas uma. Também foi suprimida a cena em que os companheiros de Odisseu fogem da caverna sob o ventre dos carneiros. Carmen Soares sinaliza que a grande modificação de Eurípides, além de Sileno, é "a presença dominadora de Baco. Evocado nas manifestações dos seus jovens e entusiastas seguidores, os Sátiros" (SOARES, 2009, p. 11). As mudanças de Eurípides são convenientes não só ao formato do drama satírico, mas também à construção singular de seu Polifemo.

$\mathrm{O}$ artigo é constituído no rastro da questão: quais são as características que constroem a selvageria do Polifemo de Eurípides? É então analisado o encontro entre o Ciclope e Odisseu, dedicando-se principalmente ao $1^{\circ}$ episódio (82-355), no qual é estabelecido um ágon, um embate retórico, entre o selvagem e o astuto, em que características de selvageria são reafirmadas pelo Ciclope. $\mathrm{O}$ que nos propomos é rastrear um elemento político no drama satírico, indicando como Eurípides reaproveita a célebre passagem homérica para aglutinar valores antidemocráticos ao ogro canibal. O texto divide-se em três partes: As fronteiras do selvagem, em que são examinados os fundamentos do status do selvagem para o cidadão ateniense; A língua de Odisseu e a boca de Polifemo, em que são apresentadas características do antagonismo das duas personagens; e A política do canibal, centrado no agón da trama, analisando os argumentos do embate entre Odisseu e Polifemo.

\section{As fronteiras do selvagem}

O século V a.C., de acordo com Jacqueline de Romilly (1966), trouxe o que poderíamos modernamente chamar de um "l'esprit du progrès" ao pensamento grego. Ainda que a ideia de tempo ascendente seja exterior e anacrônica para a antiguidade, os textos do século $\mathrm{V}$, do teatro à sofística, passando pela medicina, testemunham de acordo com a autora um período de invenção, discussão e problematização não vivenciados anteriormente, fruto da vitória das guerras grego-pérsicas e do desenvolvimento de significados

9 Venezia (2007) analisa versões que nos restaram, fragmentos ou descrições como o Ciclope de Epicarmo, a Odisseia de Cratino (439-437 a.C.), o Ciclope de Callia (434 a.C.), a versão de Filoxeno, obra datada provavelmente entre 390 a.C. e 388 a.C., na qual o Ciclope se apaixona pela ninfa Galateia, e também o Ciclope de Antífanes, da chamada Comédia Nova.

10 No original: "un mostro crudele e un astuto ingannatore". 
políticos. Contudo, tal harmonia e perspectiva de progresso eram vigiadas por um inimigo que habitava as margens.

Dos perigos que rondam o imaginário da pólis, nenhum é tão corrosivo à estabilidade do que a figura do selvagem. Ele configura uma monstruosidade, um ser não domesticado e não seguidor das leis que constroem o consenso da vida pública. A metamorfose do selvagem é sempre construída por um sujeito ao olhar o outro, como esclarece Charpentier (2015, p. 10): “um selvagem que, segundo o caso, pode se revelar lugar, figura humana ou divina, ou mesmo simplesmente espaço e que pertence tanto a um universo vegetal, animal ou humano"11.

A figura que encarna todas as referências do selvagem é a do Ciclope. Na Odisseia, eles são caracterizados como "arrogantes e sem lei" (Odisseia, IX, 106), que "nada semeiam" (Odisseia, IX, 106). Para eles "não há assembleias deliberativas nem leis" (Odisseia, IX, 112). Se os Ciclopes vivem dessa maneira, Polifemo é ainda mais distante de seus companheiros: "aí dormia um homem monstruoso" (Odisseia, IX, 187), "mantinha-se afastado de todos e não obedecia a lei alguma" (Odisseia, IX, 189), "um homem vestido de grande / violência, selvagem [ă $\gamma p ı v]$, desconhecedor de leis e justiça” (Odisseia, IX, 214-15).

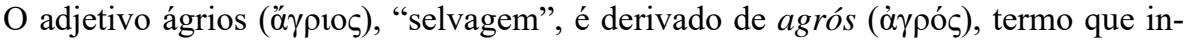
dicava o campo. Pierre Chantraine (1999, p. 15) destaca que ágrios era dito de animais, homens, sentimentos selvagens e que tomou o sentido de feroz, tornando o adjetivo impróprio para designar o campestre, significado primário de agrós, e que para isso surgiu

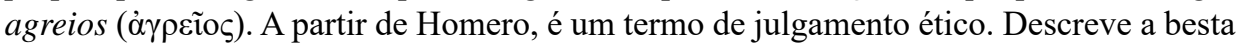
literalmente selvagem, mas é também uma palavra valorativa, indicando comportamento selvagem, incivilizado.

A solidão do Polifemo homérico amplifica ainda mais a selvageria e salienta a sua brutalidade. George Minois em sua História da solidão e dos solitários discute que o mundo social ateniense é avesso à solidão. As próprias sanções penais como o ostracismo e a atimia são penas de isolamento do mundo social, de distanciamento (MINOIS, 2019, p. 13). Nos primeiros versos da peça, Sileno descreve sua condição e salienta a solidão dos Ciclopes:

Os filhos caolhos do deus do mar, os Ciclopes homicidas, habitam antros solitários. Aprisionados por um deles, somos escravos em sua gruta. Aquele a quem servimos, chama-se Polifemo. E em vez de evoés nas festas de Baco, apascentamos os rebanhos de um ímpio

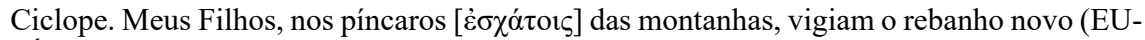
RÍPEDES, 1987, 22-28) $)^{12}$.

Na primeira definição do Ciclope euripidiano, ecoam os traços homéricos, a selvageria, a solidão e a oposição ao mundo civilizado. David Konstan observa a construção ambígua do Ciclope:

11 No original: "un sauvage qui selon les cas peut se révéler lieu, figure humaine ou divine, ou même simplement espace et qui appartient aussi bien à un univers végétal, animal ou humain".

12 Os últimos anos têm sido fecundos em traduções do Ciclope de Eurípides. A primeira tradução e a que utilizamos para o artigo foi a de Junito Brandão (1987), que por duas décadas permaneceu a única. Em 2009, a tradução da portuguesa Carmen L. Soares destacou-se por trazer grande aporte bibliográfico, com fartas notas. JAA Torrano, em 2015, traduziu o Ciclope em sua tradução completa de Eurípides. Em 2016, Guilherme de Faria Rodrigues defendeu uma dissertação de tradução com a peça e, em 2017, Vanessa Ribeiro Brandão elaborou uma tese de tradução dramática da peça. 
O status de Polifemo é ambíguo, e dessa ambiguidade depende a questão de seu comportamento ser monstruoso ou natural. A resolução dessas questões não tomará a forma de um conjunto de definições ou proposições, pois esse não é o caminho da literatura. Em vez disso, a questão do monstruoso, e da fera e da humanidade, será colocada em um complexo de oposições, algumas das quais serão valorizadas, enquanto outras, como o próprio esquema do Ciclope, são desvalorizadas (KONSTAN, 1990, p. 89) ${ }^{13}$.

Nesse esquema de oposições, de luz e sombras, de um negativo selvagem e de um positivo civilizado, é estabelecido um dos pontos centrais da identidade grega. Christine Mauduit (2006, p. 9) defende que a oposição entre selvageria e civilização era fundamental na construção da identidade do homem grego arcaico. O outro, como ser barbarizado e oposto, é figura central na qualificação sobre si mesmo. A selvageria ao estar oposta à ordem civilizada constitui-se um códex organizador. Nas supostas ausências do selvagem, o cidadão reconhece as próprias leis e regras morais. Para a autora, "a palavra que exprime a ideia de selvagem em grego comporta inicialmente um valor espacial, que se poderia qualificar como objetivo, antes de se tornar um julgamento de valor, quando é empregado pelo homem civilizado para designar a imagem inversa dele mesmo" (ibid., p. 10) ${ }^{14}$.

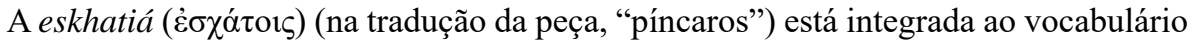
do selvagem, daquilo distante da cidade. Ela é o oposto do centro urbano (asty) e também está separada da khôra, o território da periferia. A normalidade não habita esses confins. A eskhatiá é onde são abandonados os indesejáveis. É o terreno do impróprio, onde habita aquilo que não pertence à lógica do centro. Louis Robert descreve a eskhatiá desta forma:

As $\varepsilon \sigma \chi \alpha \tau \imath \alpha i ́$ em uma cidade grega são a região além dos campos cultivados, das propriedades e das fazendas que ocupam as planícies ou os vales; é a região "na extremidade", as terras de fraco rendimento e de utilização difícil ou intermitente, perto das montanhas ou nas montanhas que sempre cercam o território de uma cidade grega. Elas são contíguas à região fronteiriça [...], essa região de montanhas e florestas que separam dois territórios de cidades, deixada ao uso dos pastores, lenhadores e carvoeiros (ROBERT, 1960, p. 304-305) ${ }^{15}$.

A definição de ágrios é construída a partir das fronteiras. Charpentier $(2015$, p. 11) argumenta que a fronteira na Grécia Antiga tem uma simbologia de diferenciação, uma realidade valorativa, um papel e um valor especial, já que em vários casos, como o do Ciclope, é ela que define a diferença entre o animalesco e o normal.

13 No original: "the status of Polyphemus is ambiguous, and upon this ambiguity depends the question of whether his behavior is monstrous or natural. The resolution of these questions will not take the form of a set of definitions or propositions, for this is not the way of literature. Rather, the question of the monstrous, and of beast and making, will take its place in a complex of oppositions, some of which will be valorized, while others, like the Cyclops' own scheme, are devalued".

14 No original: "le mot qui exprime l'idée de sauvage en grec comporte donc initialement une valeur spatiale, que l'on pourrait qualifier d'objective, avant de devenir un jugement de valeur, lorsqu'il est employé par l'homme civilisé pour désigner l'image inversée de lui-même".

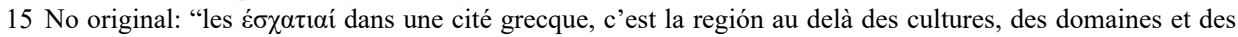
fermes qui occupent les plaines ou les vallons ; c'est la région « au bout», les terres de mauvais rapport et d'utilisation difficile ou intermittente, vers la montagne ou dans la montagne qui borde toujours le territoire d'une cité grecque ; elles jouxtent la région frontière [...], cette région de montagnes et de forêts qui sépare deux territoires de cités, laissée à l'usage des bergers, des bûcherons et des charbonniers". 
Outra figura que habita o mais distante, em outro espaço que não o do centro urbano, e que também se torna ambígua é a do homem do campo: o agroikos. Philippe Borgeaud argumenta que o homem citadino (astéios) mantinha uma oposição com o homem do campo (agroikos). O camponês mantém por sua distância e não por seus hábitos uma proximidade com a fronteira selvagem, assim sendo comparado com o outro extremo, que não o urbano: "O agroikos é de fato suscetível a se confundir com o selvagem, o brutal, o ágrios. Ele carrega uma parte de violência, de húbris, que exige ser civilizada, aprisionada" (BORGEAUD, 1993, p. 275) ${ }^{16}$.

A oposição com o civilizado, com o citadino, é essencial à definição do selvagem. $\mathrm{O}$ selvagem, quer se trate do homem selvagem ou do espaço selvagem, não existe verdadeiramente por si mesmo. Ele nasce de um julgamento externo (aquele do civilizado que dedica a ele um olhar). Charpentier (2004, p. 5) aponta que o selvagem como categoria é colocado em uma rede de qualificações depreciativas, em um julgamento negativo que destaca sua falta de civilização. No entanto, ele funciona como elemento estruturante do discurso sobre a cidade.

Tal oposição estruturante demarca o centro, as bordas e as permeabilidades, qualifica a ameaça externa ou interna. Os espaços e as fronteiras da selvageria interrogam a cidade, seja à sua margem ou irrompendo em seu interior como uma crise. O selvagem parte do elemento temível para se tornar um argumento ideológico, daquilo que deve ser mantido fora ou daquilo que constrange a ordem.

Fabio Turato (1979) argumenta que é possível encontrar uma "ideologia do selvagem" na Atenas do século V a.C. Apesar de a selvageria ser uma oposição recorrente na cultura grega, a figura foi constantemente reatualizada para perpetuar certos vetores de um desenvolvimento ateniense, defendidos principalmente no âmbito da cultura pericleana na segunda metade do século $\mathrm{V}$ a.C.:

É claro que esta projeção em uma vaga proto-história de uma "missão civilizatória" de Atenas acaba por degradar ao papel de metáfora propagandística aquela oposição entre a esfera da animalidade e aquela do homem da cidade, entre a condição selvagem e a "civil", que na cultura pericleana, embora marcada por uma cifra ideológica orgânica em um projeto político de essência conservadora, havia assumido a intuição, se não de um desenvolvimento coerente, de um projeto formado por etapas progressivas (TURATO, 1979, p. 33) ${ }^{17}$.

A oposição cidade/selvagem fornecia um elemento ideológico, que se dedica a congregar valores políticos e ao mesmo tempo manter afastados os elementos periféricos. Borgeaud (1993) lembra que a oposição entre citadino (astéios) e camponês (agroikos), que depreciava a figura do homem do campo, foi uma invenção do século $\mathrm{V}$ a.C.:

A oposição entre cidade e campo aparece assim como uma invenção do século V, em decorrência da situação muito particular criada pelas guerras do Peloponeso. Até então, o cidadão

16 No original: "l'agroikos est en effet susceptible de se confondre avec le sauvage, le brutal, l'agrios. Il porte en lui une part de violence, d'hybris, que demande à être cívilisée, apprivoisée".

17 No original: "certo questa proiezione in una vaga protostoria d'una "missione civilizzatrice" di Atene finisce col degradare al ruolo di metafora propagandistica quell'opossizione tra la sfera dell'animalità e quella dell'uomo della città, tra la condizione selvaggia e quella "civille", che nella cultura periclea, pur contrassegnata da una cifra ideologica organica ad un progetto politico nella sua essenza conservatore, aveva preso le mosse dell'intuizione, se non d'uno sviluppo coerente, d'un processo scandito da tappe progressive". 
ateniense com frequência habitava fora de Atenas, nos démes, e só ia à cidade para assuntos específicos (econômicos, políticos e religiosos). Sua vida era ligada ao trabalho em suas terras (BORGEAUD, 1993, p. 271) ${ }^{18}$.

Assim, a figura do selvagem é utilizada como um tópos para salientar constantemente o que não deve permanecer na pólis, o que deve ser deixado no entorno. As fronteiras do selvagem não são apenas as fronteiras distantes, mas identitárias, nas quais os emblemas da pólis devem ser salvaguardados contra um outro que se personifica e apresenta argumentos claros de sua polaridade. No próximo tópico, abordaremos como o Ciclope de Eurípides aglutina no contraste entre Polifemo e Odisseu oposições que pertencem à dualidade do selvagem/civilizado.

\section{A língua de Odisseu e a boca de Polifemo}

Para seguir o nosso questionamento inicial, sobre as características que constroem a selvageria de Polifemo, é preciso argumentar sobre o status simbólico de Odisseu e do Ciclope no drama. David Konstan argumenta sobre a singularidade do viajante na peça: "os únicos humanos no palco, estritamente falando, são Odisseu e seus homens. Não obstante as distinções - e elas são importantes — entre os Sátiros e os Ciclopes, ambos representam aspectos do bestial e nisso se parecem. Odisseu pode chamar a ambos de feras" (KONSTAN, 1990, p. 89) ${ }^{19}$. Ao chegar à ilha, em situação de fome, Odisseu (na tradução, Ulisses) encontra Sileno e estabelece a comunicação:

Ulisses: Estrangeiros, podeis nos informar onde encontrar água corrente para matar nossa sede e quem poderia vender alimentos a marinheiros famintos? Que é isso? Parece que chegamos à terra de Brômio. Vejo junto à caverna uma multidão de Sátiros. Saúdo primeiramente o mais velho.

Sileno: Saúde, estrangeiro! Dize-nos quem és e qual a tua pátria.

Ulisses: Sou Ulisses de Ítaca, rei dos Cefalênios.

Sileno: Conheço esse herói, tagarela e astuto, sangue de Sísifo! [oĩ $\delta$ ’ớv $\delta \rho \alpha, \kappa \rho o ́ \tau \alpha \lambda o v$

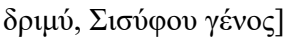

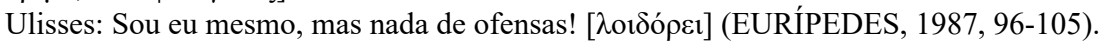

Em seu clássico Les mythes d'Homère et la pensée grecque, Buffière (1956, p. 365) defende que a figura de Odisseu na Odisseia não deve ser tomada apenas como um herói romanesco, que vagueia de aventura em aventura, mas como "um tipo ideal de humanidade, a figura estilizada da sabedoria" ${ }^{20}$. Contudo, a caracterização que Sileno faz de Odisseu não ecoa a descrição do Odisseu da épica. Ele é descrito como: herói (homem) (’̊vท́ $\rho)$,

18 No original: “l'opposition ville-campagne apparaît ainsi comme une invention du V siècle, issue de la situation trés particuliére créee par les guerres du Péloponnèse. Jusqu'alors le citoyen athénien, le plus souvent, habitait hors d'Athènes, dans les dèmes, et ne se rendait en ville que pour affaires (économiques, politiques et religieuses). Sa vie était liée au travail de ses terres".

19 No original: "the only humans on stage, speaking strictly, are Odysseus and his men. Whatever the distinctions - and they are important - between the Satyrs and Cyclopes, they both stand as aspects of bestial and in this resemble each other. Odysseus can refer to both as beasts".

20 No original: "un type ideal d'humanité, la figure stylisée de la sagesse".

52 - Conexão Letras, Porto Alegre, v. 15, n. 24, p. 45-65, jul-dez. 2020. 


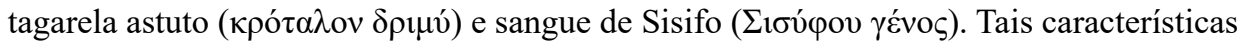
compõem uma rede depreciativa do herói.

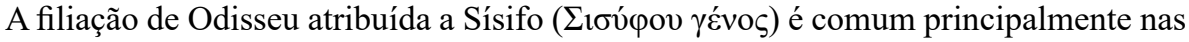
tragédias quando se deseja caluniar o herói. A expressão "tagarela astuto" é uma tradução

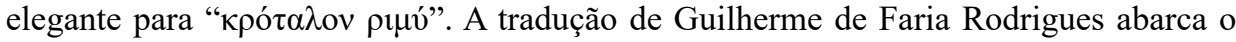
significado mais depreciativo da expressão: "uma matraca afiada" (RODRIGUES, 2016, p. 92). A palavra krotalum de acordo com William Smith (1870, p. 370) é um instrumento de percussão, um tipo de címbalo, mas parecido com uma castanhola. A descrição negativa de Odisseu, associado a uma cacofonia de ruídos ou a uma cepa amaldiçoada como a de Sísifo, é um discurso desenvolvido ao longo do século V a.C.

Silvia Montiglio (2011) destaca a ascensão de representações negativas do herói e a sua associação com políticos e sofistas, principalmente no final do século V a.C., afirmando que se formou uma representação de um Odisseu demagogo relacionada a um contexto de crise e desencanto com a política e com o poder das palavras. A autora ressalta a reconfiguração das características de Odisseu e a revalorização de traços que antes eram neutros ou positivos, como a sua relação com o kérdos e sua postura de tirar vantagens de todas as situações:

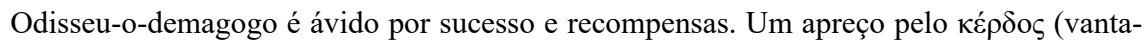
gem, ganho) já o caracteriza na Ilíada e na Odisseia, mas sem uma culpabilização. Embora

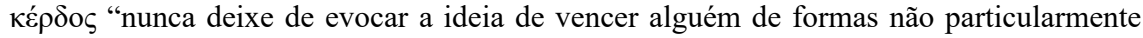
heróicas", em Homero sua conexão privilegiada com Odisseu em geral não é depreciativa e pode até mesmo ser elogiosa (MONTIGLIO, 2011, p. 10) ${ }^{21}$.

Se levarmos em conta a datação de Seaford (1982) que coloca o Ciclope no final do século V a.C., podemos notar semelhanças entre a descrição do herói por Sileno e a descrição que Sófocles faz de Odisseu no Filoctetes (409 a.C.) 22. A frase de Odisseu — "Sou eu mesmo, mas nada de ofensas!" (Ciclope, 105) — talvez tivesse um profundo impacto cômico nos ouvintes. A personagem de Eurípides não discorda das características, assume-se como "homem de matraca afiada" e pondera para encerrar a conversa: nada de pro-

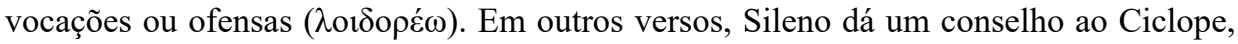
apontando as vantagens de devorá-lo:

Sileno: (Ao Ciclope) Quero te dar um conselho: (mostrando Ulisses) não deixes nada da

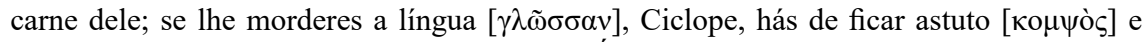
serás o maior dos tagarelas [ $\lambda \alpha \lambda i ́ \sigma \tau \alpha \tau o \zeta]$ (EURÍPEDES, 1987, 313-315).

Mais uma vez Sileno faz referência à habilidade persuasória de Odisseu, indicando a

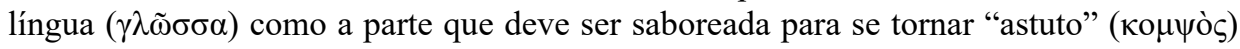
e tagarela ( $\lambda \alpha \lambda i ́ \sigma \tau \alpha \tau o \zeta)$. Guilherme de Faria Rodrigues, em seu trabalho de tradução,

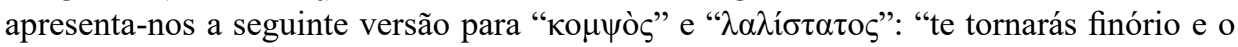

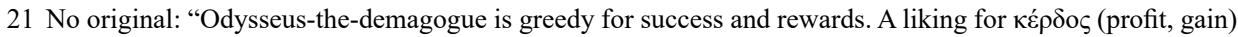

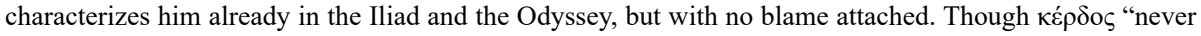
ceases to evoke the idea of getting the better of someone in not particularly heroic ways," in Homer Odysseus' privileged connection with it on the whole is not disparaging and can even be complimentary".

22 Para uma análise sobre o Odisseu no Filoctetes de Sófocles, ver Dagios (2019). 
mais falador, Ciclope" (RODRIGUES, 2016, p. 109). De acordo com o tradutor, o termo “ко $\mu \psi$ ó $\varsigma "$ em Eurípides carrega um tom pejorativo, sendo também usado em outras peças como As suplicantes (426) e As traquínias (651), e que na mesma linha de degradação é usado “ $\lambda \alpha \lambda i ́ \sigma \tau \alpha \tau o \zeta "$, que é uma espécie de falatório (ibid., p. 109).

$\mathrm{O}$ símbolo da língua como identificação de um falador ou de um homem perigoso no uso da retórica é comum nas comédias e nas tragédias. Rosenbloom aponta que a imagem da glóssa (língua) ganhou importância no século V a.C. como elemento de crítica aos oradores, aos discursos enganosos e em benefício próprio, sendo usada para uma caracterização pejorativa da eloquência e dos seus praticantes:

A imagem da retórica como língua associa os oradores com uma parte do corpo que é incapaz de representar o corpo inteiro ou um corpo político integrado; a língua tem associações culturais com sintomas de doenças, prazeres poluentes e rituais de sacrifício. Enquanto uma pólis pode falar com uma voz coletiva, ela não pode falar com uma "língua" coletiva; conceber uma performance oral em termos da língua enfatiza a perigosa dependência da pólis de atos discursivos dos indivíduos e o seu poder de criar realidades em performances momentâneas que nulificam a experiência acumulada do passado (ROSENBLOOM, 2009, p. 200) $)^{23}$.

Se a língua é o que mais preocupa Sileno na anatomia de Odisseu, por outro lado, o avantajado Ciclope não causa pavor somente por seu único olho — o "ciclope caolho"

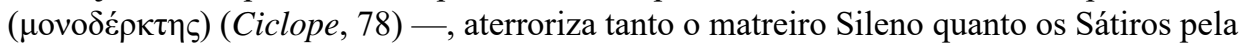
sua aterrorizante boca, que representa sua fome:

Sileno: Vejo junto à praia a quilha de um navio grego. Os remadores e seu chefe dirigem-se para nossa gruta. Penduradas no pescoço trazem ânforas vazias: necessitam de víveres. Trazem ainda jarros. Pobres estrangeiros! Quem são eles? Desconhecem a Polifemo, nosso patrão, caso contrário não se lançariam desgraçadamente nas queixadas do

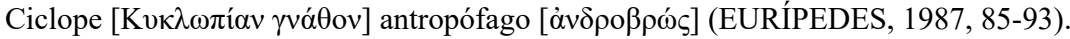

Em relação à monstruosidade de Polifemo, ela é citada duas vezes na Odisseia: "com medo da voz profunda e do ser monstruoso [ $\pi \dot{\lambda} \lambda \omega \rho \circ v]$ " (Odisseia, IX, 257) e "Ciclope, esse monstro [ $\pi \dot{\varepsilon} \lambda \omega \rho$ ] sem lei alguma dormia" (Odisseia, IX, 428). Camila Zanon (2016) faz uma profunda análise sobre o sentido dos termos " $\pi \dot{\varepsilon} \lambda \omega \rho$ " e " $\pi \dot{\varepsilon} \lambda \omega \rho \circ \nu$ ", explicando que essas palavras são geralmente traduzidas como monstruoso, mas se referem mais ao tamanho de Polifemo do que propriamente o sentido que o termo monstro possui em

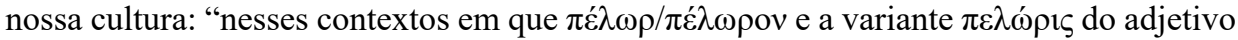
se referem a Polifemo, eles estão claramente relacionados à enormidade do ciclope e ao espanto que ela causa" (ibid., p. 81).

No Ciclope de Eurípides, é explorado o vocabulário referente à animalidade de Polifemo. Ao estabelecer diálogo com o chefe dos Sátiros, Odisseu pergunta: "a quem pertence

23 No original: "the trope of rhetoric as tongue associates orators with a body part that is incapable of standing for a whole body or an integrated body politic; the tongue has cultural associations with symptoms of disease, polluting pleasures, and sacrificial ritual. While a polis may speak with a collective voice, it cannot speak with a collective "tongue"; to conceive of oral performance in terms of the tongue stresses the dangerous dependence of the polis upon individuals' speech-acts and their power to create realities in momentary performances that nullify the accumulated experience of the past". 
essas terras? A feras [ $\theta \eta \rho \tilde{\omega} v]$, por acaso?" (Ciclope, 117). Ao sair da caverna de Polifemo depois do violento banquete canibal, Odisseu continua com o mesmo tipo de tratamento:

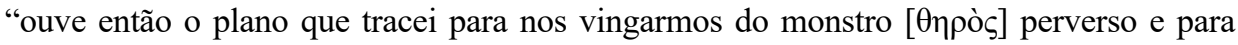
libertar-se da escravidão" (Ciclope, 441-442). O Ciclope é esse ser animalizado para Odis-

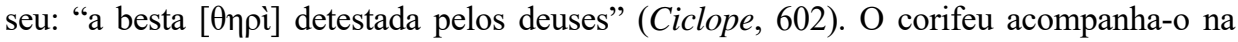

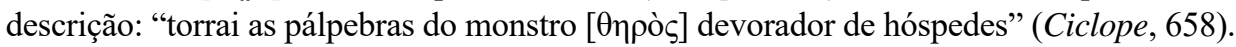

A boca $(\gamma v \alpha$ á $\theta$ os) de Polifemo é a sua principal característica depois do seu olho, por

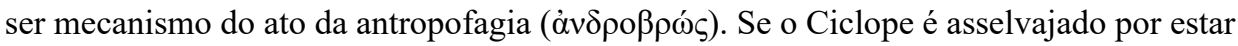
na eskhatiá, não plantar e não produzir o pão e o vinho, é na antropofagia que ele se torna um ser monstruoso. Assim são destacadas as ausências de Polifemo:

Ulisses: Que país é este e quem o habita?

Sileno: É o Etna, o mais alto monte da Sicília.

Ulisses: Onde estão as muralhas e fortificações da cidade [ $\pi$ ó $\lambda \varepsilon \omega \varsigma \pi v \rho \gamma \omega ́ \mu \alpha \tau \alpha]$ ?

Sileno: Não existe. Neste monte não habitam seres humanos [ $\alpha \dot{v} \theta \rho \dot{\pi} \omega \nu$ ], estrangeiros.

Ulisses: A quem pertence essas terras? A feras [ $\theta \eta \rho \tilde{\omega} v]$, por acaso?

Sileno: Aos Ciclopes que habitam antros [ớv $\tau \rho]$, não casas.

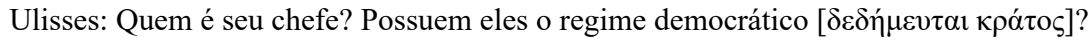

Sileno: São pastores errantes e ninguém obedece a ninguém em nada.

Ulisses: De que se alimentam? Cultivam o trigo, consagrado a Deméter?

Sileno: Alimentam-se de leite, queijo e de carne de carneiro.

Ulisses: Não bebem o suco da videira, consagrado a Brômio?

Sileno: De modo algum. Também não existe a dança nestes locais por eles habitados.

Ulisses: São hospitaleiros e benévolos com os estrangeiros?

Sileno: Os estrangeiros, dizem eles, têm uma carne saborosíssima.

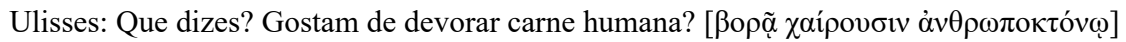

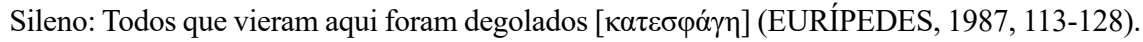

Odisseu trava uma entrevista investigatória, que é construída nos moldes dos ecos homéricos. As perguntas revelam uma antropologia do selvagem. Odisseu vai indagando progressivamente sobre os elementos que constroem um entorno civilizatório e vai percebendo a negação desses. Os Ciclopes são desprovidos da cidade fortificada, morada construída não há, eles habitam cavernas, não possuem o regime democrático, não se alimentam de pão ou bebem o vinho. Também não dançam, o que pode ser interpretado como uma referência aos festivais dionisíacos, não possuem apreço pelas leis de receber bem os estrangeiros e finalmente o que é mais terrível na composição desse quadro: os habitantes devoram carne humana.

É estabelecida nesse diálogo a reafirmação dos pressupostos identitários gregos. Carol Dougherty (1999) descreve que a postura do Odisseu de Eurípides pode ser descrita como uma "etnografia" condizente com as noções gregas de expansão:

Este é o discurso etnográfico que Eurípides apropria da Odisseia para sua peça satírica do século V - um conjunto de expectativas narrativas sobre como é o mundo além-mar juntamente com uma estrutura heterológica de pensamento sobre a relação entre esse mundo e o lar. A partir do período arcaico, conforme os gregos continuaram a explorar e colonizar territórios além-mar, a Odisseia teve um papel importante no pensamento grego como um 
modelo dominante para a representação de viagens e encontros em novos mundos" (DOUGHERTY, 1999, p. 319) ${ }^{24}$.

No entanto, o Ciclope não é o único que está no círculo do selvagem. Os Sátiros também são monstruosos, não por seus atos, mas por sua anatomia: meio homem, meio bode. Tereza Virgínia Ribeiro Barbosa (2009) comenta sobre o caráter dos seguidores de Dioniso, incluindo os Sátiros: "o séquito desse deus, [...] os sátiros inclusive, constitui-se como uma corrente de potências indisciplinadas da vida. Vir em bando como forma múltipla torna-os mais assustadores: ameaça movente, porque sempre agitados e embriagados" (ibid., p. 26). A autora coloca os Sátiros na paisagem do selvagem, mas argumenta que eles têm diferenças quando comparados com outras criaturas como o centauro: "o sátiro é esperto, audacioso porque não avalia bem os perigos, mas é ágil para a fuga. É fera agreste, mas, ainda assim, delicadamente malandro, diferente do centauro que é bruto é forte" (ibid., p. 26). A obscenidade dos Sátiros, seu comportamento lascivo e suas constantes aspirações de prazer são no dizer da autora uma "paródia humana em seus sucessos e fracassos" (ibid., p. 28).

Nesse entorno de selvagens, do Ciclope e dos Sátiros, a presença do viajante evoca uma ordem civilizatória. Konstan ressalta que Odisseu deseja antes de tudo efetuar comércio, uma relação de troca: "a linguagem do comércio permeia as cenas iniciais entre Odisseu, Sileno e Polifemo, desde o momento em que Odisseu entra em cena, perguntando se haveria alguém disposto a vender comida a marinheiros necessitados" (KONSTAN, 1990, p. 89-90) $)^{25}$.

No texto euripidiano, Odisseu e Polifemo conservam as posições homéricas de oposição, mas duas figuras anatômicas — a língua e a boca — conduzem a caracterização desses opostos. Além de acrescentar associações negativas de Odisseu pertencentes ao vocabulário discursivo do século V a.C., Eurípides agrega na fala do Ciclope mais uma característica, que é a do selvagem-político, abordada na próxima seção.

\section{A política do canibal}

Como apontado anteriormente, o final do século V a.C. foi marcado por um período de crise em que a metáfora do selvagem é utilizada de forma ideológica. Fabio Turato (1979) defende que a figura do selvagem é compreendida principalmente como "inimigo da cidade", por ameaçar a ideologia progressista do século de Péricles. O selvagem como um elemento desagregador é também construtor da identidade grega.

Podem ser identificadas três grandes mudanças no drama satírico de Eurípides quando comparado com o enredo homérico: a primeira é a figura de Sileno e dos Sátiros, a segun-

24 No original: "this is the ethnographic discourse that Euripides appropriates from the Odyssey for his fifth-century satyr play - a set of narrative expectations about what the world overseas looks like together with a heterological structure for thinking about the relationship between that world and home. From the archaic period on, as the Greeks continued to explore and settle territory overseas, the Odyssey served an important role in Greek thought as an authoritative model for representing new world travels and encounters".

25 No original: "the language of commerce permeates the opening scenes between Odysseus, Silenus, and Polyphemus, from the moment when Odysseys steps on the stage, inquiring whether anyone might be willing to sell food to needy sailors". 
da é que a trama não se passa somente em lugar distante, mas aos pés do monte Etna e a terceira é que, além de manter as características conhecidas do Ciclope, como as descritas no tópico anterior, Eurípides aglutina um novo elemento político.

A inserção de Sileno e do seu bando de Sátiros pode ser interpretada como uma obrigatoriedade do gênero, já que estamos no terreno do drama satírico e existiam princípios que deveriam ser respeitados na reorganização da narrativa. Por outro lado, David Konstan (1990) argumenta que a maneira como a peça foi construída qualifica a participação de Sileno e dos Sátiros, fazendo-os desempenhar papéis que ultrapassam o elemento cênico, pois contribuem para uma reorganização das forças da peça. Odisseu e seus companheiros são os elementos humanos, Polifemo desempenha o papel mais monstruoso pela antropofagia e Sileno guarda características tanto humanas quanto monstruosas (ibid., p. 89).

Patrick O’Sullivan (2012, p. 170) destaca que a menção à Sicília e ao Etna é indicada por vários comentadores como um indício que ajuda a datar o drama satírico no final do século V a.C. A ligação com a desastrosa expedição à Sicília em 412 a.C. seria o mote para localizar um selvagem em um território que provocou tantos dissabores e uma profunda cicatriz ao público ateniense. Nesse eco das expedições sicilianas, Michael Vickers defende que o Ciclope euripidiano possui referências a Alcibíades, principalmente na caracterização de Sileno e Odisseu: "No Ciclope, Sileno compartilha o fardo da representação de Alcibíades com Odisseu. É apropriado representar assim Alcibíades, o grande beberrão, e há uma razão estilística adicional para pensar que a intenção era que Sileno representasse nosso herói" (VICKERS, 1987, p. 89) ${ }^{26}$. O autor atribui referências linguísticas demasiado vagas que ligariam a linguagem do Alcibíades tucidiano à linguagem de Sileno na peça. Discordamos das aproximações lineares de Vickers (1987), mas reconhecemos que é possível algumas identificações mais amplas com a Sicília como as indicadas por Sullivan (2012).

No que concerne ao terceiro elemento de mudança, aquele em que concentramos nossa questão sobre as características que constroem a selvageria do Polifemo de Eurípides, é preciso atentar para o ágon mantido entre Odisseu e o Ciclope. De acordo com O'Sullivan \& Collard, os discursos das duas personagens podem ser considerados um ágon dentro da peça:

Independentemente de esses discursos de Odisseu e Polifemo constituírem um ágon formal ou não, essa interação entre herói e monstro apresenta duas visões de mundo altamente contrastantes. Nesse nível, ao menos, ela difere dos agones mais típicos de Eurípides, em que são feitas tentativas de justificar ações passadas em face de uma longa acusação ou denúncia (O’SULLIVAN; COLLARD, 2013, p. 166) ${ }^{27}$.

No primeiro momento do embate, o viajante Odisseu começa uma longa argumentação depois de encontrar Polifemo, versando sobre a Guerra de Troia, as leis de hospitalidade e os atos ímpios:

26 No original: "in the Cyclops, Silenus shares the burden of representing Alcibiades with Odysseus. It is appropriate to have Alcibiades the arch-boozer represented thus, and there is an additional stylistic reason to think that Silenus is meant to stand for our hero".

27 No original: "whether or not these speeches by Odysseus and Polyphemus comprise a formal agôn or debate, this exchange between hero and monster presents two world-views in sharp contrast to each other. On this level at least it differs from the more typical of Euripidean agônes where attempts are made at justifying past actions in the face of a lengthy accusation or denunciation". 
Ulisses: Um deus é o responsável. Disso não acuses a nenhum dos mortais. (Com ar de súplica) Quanto a nós, ó ilustre filho do deus do mar, atende à nossa súplica e às nossas palavras sinceras: não concebas a idéia de matar em teu antro a pessoas que aqui chegaram

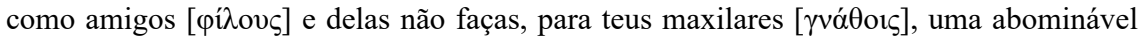
refeição! Nós, senhor, defendemos os templos de teu pai, guardando-os bem no interior da terra grega. A sagrada enseada do Tênaro permanece inviolável, assim como os altos refúgios de Maléia; em Súnio estão a salvo o rochedo marchetado de prata da deusa Atená, bem como os esconderijos de Geresto. Nem tampouco a Grécia, o que seria injúria grave, permitimos fosse entregue aos frígios. Também tu participas desses bens, porque é grega a terra, cujas profundezas habitas, ao pé do Etna, este rochedo que vomita fogo. Existe, por outro lado, em relação aos mortais, uma lei [vónos], se é que discordas de minha argumen-

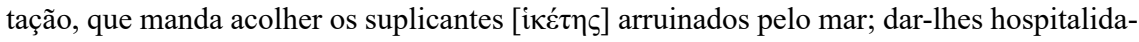
de [ $\xi \dot{\varepsilon} v i \alpha$ ] ; fornecer-lhes vestuário e não cravar-lhes os membros em grossos espetos para

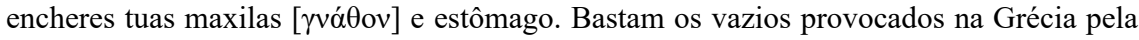
guerra de Príamo, que bebeu o sangue de tantos mortos tombados pela lança. Tróia privou esposas de seus maridos, anciãs de seus filhos e destruiu velhos encanecidos. Se os que restam forem por ti assados e devorados num monstruoso festim, que há de acontecer? Mas,

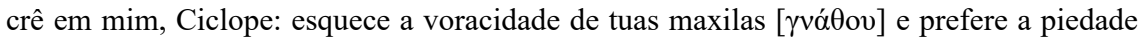

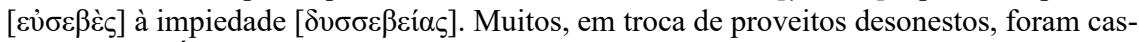
tigados (EURÍPEDES, 1987, 285-312).

Odisseu tangencia o motivo da guerra troiana lançando a responsabilidade aos deuses. O argumento não é novo, repete o de Agamêmnon na Ilíada (XIX, 86). Em seguida, re-

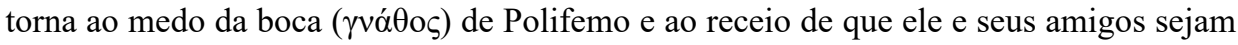
triturados pelas mandíbulas terríveis do selvagem. $\mathrm{O}$ argumento da amizade — "pessoas que chegaram como amigos" ( $\varphi$ ínovs, 288) - revela-se mais complexo, pois o phílos defendido por Odisseu pode ser interpretado como reivindicação da xénia ( $\xi$ ćvió, 301).

Em seu livro sobre a amizade na antiguidade, Konstan ressalta sobre a relação entre Phílos e Xénoi: “O adjetivo phílos, em particular, seleciona entre xénoi, ou desconhecidos, aqueles com quem as relações de hospitalidade são reconhecidas" (KONSTAN, 2005, p. 52). Ao colocar-se como phílos e por extensão a relação de xénoi, que era uma relação de hospitalidade como argumento, Odisseu reivindica uma lei que garante que ele e os seus sejam bem tratados, o que obviamente exclui ser cravado em "grossos espetos" para ser devorado pelas mandíbulas ( $\gamma v \alpha ́ \theta o v)$ de Polifemo.

Paralelo à hospitalidade, é utilizado o argumento religioso da hikêteria, com a acolhi-

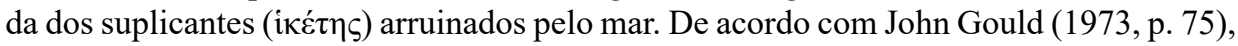
o ritual da hikêteia desempenha um importante papel no tecido social das instituições. $\mathrm{O}$ autor caracteriza o ritual da seguinte maneira: "a natureza ritual do ato depende essencialmente do contato físico com partes do corpo que, como foi defendido, seriam vistas como tendo uma santidade peculiar. Mas é possível realizar as formas verbais do ato de súplica [...] sem esse contato físico" (ibid., p. 77) ${ }^{28}$. Pela configuração da cena, é difícil imaginar que o ritual do toque tenha sido cumprido.

Odisseu lembra a Polifemo que ele e os seus companheiros merecem um bom tratamento porque defenderam o território grego e os templos sagrados. Alguns comentadores (BRANDÃO, 1987, p. 54; SOARES, 2009, p. 43) observam essa questão como um argu-

28 No original: "the ritual nature of the act depends essentially upon physical contact with parts of the body which, it has been argued, are regarded as having a peculiar sanctity. Yet it is possible to go through the verbal forms of the act of supplication [...] without such physical contact." 
mento "insólito" ou "anacronismo". A Guerra de Troia não ameaçou a Grécia continental, não colocando tais lugares em risco, e temporalmente a argumentação faz referência às Guerras Medo-Persas (490-479 a.C.). A questão mantém-se problemática, porque os textos do teatro antigo têm outra relação com as noções de temporalidade histórica. A inserção do argumento de Odisseu poderia servir para chamar a atenção do público para um jogo retórico no qual mentira se sobrepunha à verdade, fazendo justiça à fama que a figura de Odisseu adquirira no final do século $\mathrm{V}$ a.C. como um retórico político, ou também poderia servir para um efeito cômico, como era comum no drama satírico ${ }^{29}$.

Por último, e ainda assombrado pela perspectiva da boca de Polifemo, Odisseu pede

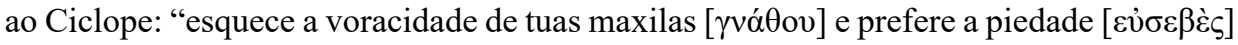

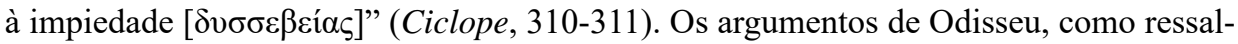
tou Carmen Soares (2009), são basicamente agrupados em três grupos: "a justiça (Dike), a súplica (Hikêteia) e a hospitalidade (Xênia)" (ibid., p. 46). Assim, são destacados argumentos que pertencem ao convívio e à pólis. Frente à selvageria do Ciclope, Odisseu apresenta os tópicos que o tornam civilizado e é como cidadão que convida Polifemo a seguir tais virtudes. Mas a resposta de Polifemo não admite tais contornos:

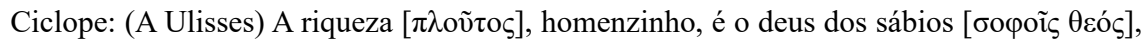

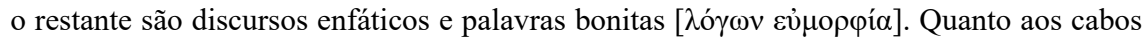
marinhos, onde habita meu pai, que passem bem! Que pretendes com tuas palavras? O raio de Zeus não o temo, estrangeiro, e não sei em que Zeus é um deus superior a mim. O resto não me preocupa e escuta por que não me preocupo com o resto. Quando das alturas ele despeja o aguaceiro, tenho neste antro o meu abrigo, onde, após me empanturrar com um bezerro assado ou com uma caça selvagem qualquer, irrigo gostosamente o baixo-ventre, esvaziando uma ânfora de leite. Depois, para rivalizar com os trovões de Zeus, encho minha túnica de estrondos! Quando Bóreas, o vento da Trácia, faz nevar, envolvo meu corpo em peles de feras, esquento-me ao fogo e a neve deixa de me preocupar. A terra, necessariamente [ảvó $\gamma \kappa \eta ̣]$, quer queira, quer não queira, produz o capim, que engorda meu rebanho.

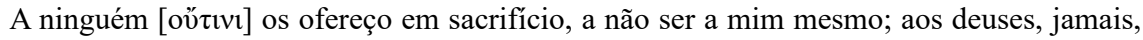
exceto ao maior dos deuses, este meu estômago! Na realidade, ter o que comer e beber diariamente este é o Zeus para as pessoas sensatas e mais, não se aborrecer com coisa alguma. No que se refere àqueles que fizeram leis para embelezar a vida humana, que se danem! Por

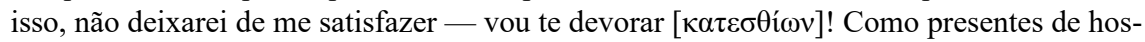
pitalidade [ $\xi \dot{\varepsilon} v 1 \alpha$ ], porque desejo ser irrepreensível, receberás fogo, (mostrando o regato) e a água paterna e um cadeirão: fervendo, ele envolverá maravilhosamente bem tuas carnes decepadas. Entrai pois e, em homenagem ao deus do antro, como se estivesse de pé em torno do altar, regalai meu estômago! (EURÍPEDES, 1987, 316-348).

Polifemo profere uma resposta em que todos os argumentos de Odisseu são negados em prol do próprio bem-estar. Os pontos civilizacionais estabelecidos por Odisseu quando encontrou Sileno no que qualificamos de uma "etnografia" são rebatidos pelo monstruoso Ciclope, que apenas reconhece a si mesmo como autoridade. Katsouris (1997) argumenta que o Polifemo de Eurípides é construído sob o signo da necessidade:

Eurípides transforma toda a situação ao empregar o termo "necessidade"

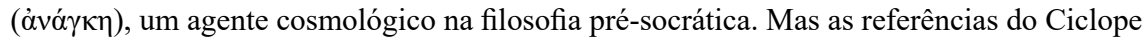

29 Para mais discussões sobre o anacronismo na tragédia grega, ver Easterling (1985). 
ao divino continuam. Na linha 335, ele repete que ele mesmo é um deus: ele oferece os animais em sacrifício a ele mesmo e seu próprio estômago, que é a maior e mais importante divindade. Autossuficiência absoluta e egoísmo absoluto o caracterizam. A riqueza é deus; quem a detém, é um deus; mas o deus mais poderoso é comer e beber à vontade todos os dias, sem se importar com nada. Claramente, ele identifica a felicidade absoluta com o hedonismo; ele apoia o hedonismo. Um ponto está ausente: sexo. Mas, aparentemente, Polifemo não precisa disso (KATSOURIS, 1997, p. 12-13) ${ }^{30}$.

Polifemo começa sua refutação defendendo a "riqueza" ( $\pi \lambda$ oṽ $\tau$ $\varsigma$ ) no lugar de "pala-

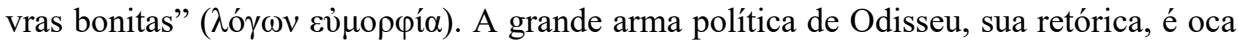
na perspectiva de mundo de Polifemo. O’Sullivan \& Collard (2013) destacam que essa postura poderia ecoar como tirana para o público: “a obsessão de Polifemo com a riqueza teria implicações tirânicas para o público contemporâneo, pois os tiranos e a ganância (especialmente por dinheiro) frequentemente andam juntos no pensamento antigo" (ibid., p. 170) ${ }^{31}$. A defesa da riqueza (ploutos) ultrapassa a situação de selvageria na ilha e ecoa no público ateniense, já que durante a peça a única moeda de troca utilizada é o vinho (Ciclope, 139). Ao pontuar o valor da riqueza em oposição aos discursos, o Ciclope faz uma defesa de um mundo pragmático em relação a qualquer lei.

A genealogia divina do filho de Poseidon não lhe desperta importância. Para fugir dos raios de Zeus e das tempestades, ele esconde-se em sua caverna, come um assado e compete com suas flatulências com os trovões divinos. A ironia euripidiana faz Polifemo

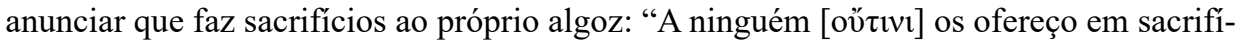
cio, a não ser a mim mesmo" (Ciclope, 334). Guilherme de Faria Rodrigues (2016, p. 110) salienta a ironia da frase: "há a presença irônica aqui de Polifemo ao mencionar que ele

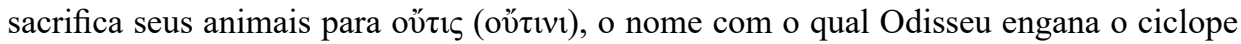
em uma das mais famosas passagens do mito".

O desprezo pelas leis comuns ganha seu ápice no que se refere a xénia, o costume

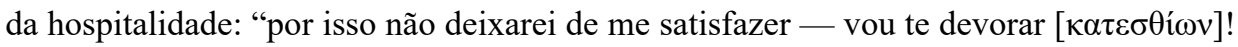
Como presentes de hospitalidade [క́ćvı $\alpha$ " (Ciclope, 341-342). Associar a ideia de devo-

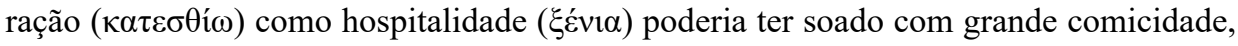
pois nos versos seguintes ele descreve como um gourmand a maneira como preparará o prato principal, seus visitantes.

O discurso de Polifemo representa uma grande mudança no conjunto de características associadas ao mito do Ciclope como descrito na Odisseia. A principal característica da selvageria de Polifemo passa a ser a negação de todos os valores políticos da pólis. $\mathrm{O}$ Ciclope, além de congregar as características já conhecidas desses habitantes dos lugares distantes (eskhatiá), como não fazer agricultura, não comer o pão, não beber o vinho, e

30 No original: "Euripides transforms the whole situation by employing the term "necessity" ( $\dot{\alpha} v \alpha \kappa \kappa \eta)$, a cosmological agent in presocratic philosophy. But the Cyclops' references to the divine go on. In line 335 he repeats that he himself is a god: he offers the animals in sacrifice to himself and his own belly, which is the greatest and most important deity. Absolute self-sufficiency, absolute egotism characterize him. Richness is god; whoever has it, is a god; but the most powerful god is eating and drinking to one's fill every day, caring about nothing. Clearly, he identifies absolute happiness with hedonism; he is a supporter of hedonism. One thing is missing: sex. But apparently Polyphemus does not need that".

31 No original: "Polyphemus' obsession with wealth would have tyrannical overtones for the contemporary audience, as tyrants and greed (especially for money) frequently go together in ancient though". 
associado ainda à antropofagia, é aglutinado a uma postura política, de se dedicar somente a si mesmo e à sua fome. Carol Dougherty (1999) argumenta que esses novos traços associados à selvageria de Polifemo fazem referência à política contemporânea de Atenas e à ideologia antidemocrática:

Muitos estudiosos leram a resposta de Polifemo a Odisseu como uma caricatura da ideologia antidemocrática contemporânea, associadas a figuras históricas como Cálicles ou Trasímaco. Em particular, a veneração de Polifemo pelo seu estômago e sua rejeição da lei são interpretadas como ecos dos argumentos em favor do hedonismo e contra a lei que Cálicles expõe no Górgias de Platão (DOUGHERTY, 1999, p. 323) 32.

O embate de Odisseu e Polifemo pode ser compreendido como evocação da questão nómos-phýsis (lei e natureza), que foi central principalmente na segunda metade do século $\mathrm{V}$ a.C. e se desenvolveu durante o século IV a.C. Odisseu advoga a nómos e a Polifemo cabe a phýsis (SOARES, 2009, p. 46). O discurso do Ciclope pode ser entendido como uma resposta sofística aos ideais da nómos. No que concerne aos deuses, Guthrie (1971) descreve o embate entre nómos e phýsis do seguinte modo a partir da perspectiva da sofística:

Os próprios deuses não têm existência na natureza, mas são um produto do artifício humano, e variam em diferentes lugares de acordo com convenções locais. $\mathrm{O}$ bem é uma coisa na natureza e outra pelo nómos; quanto à justiça, a natureza não sabe nada dela. Os homens estão sempre discutindo sobre ela e alterando-a, e cada alteração é válida a partir do momento em que é feita, devendo sua existência a convenções artificiais e não à natureza. É com teorias como essa que agitadores incitam os jovens à irreligião e à sedição, instigando-os a adotar a "vida correta de acordo com a natureza", com o que queriam dizer uma vida de ambição egoísta em vez do serviço aos semelhantes e à lei (GUTHRIE, 1971, p. 115-116)

Por outro lado, Katsouris (1997) compara a posição de Polifemo com a célebre passagem da Política de Aristóteles (1253a, 28-29), quando o filósofo qualifica um homem que vive sozinho, distante da sociedade, como uma besta ou um deus. Polifemo é na peça a personificação dessas duas figuras:

Polifemo é a encarnação de ambos. É típico que ele começa e termina seu discurso com uma referência a deuses. Seus dois últimos versos não deixam margem a dúvidas. O deus da caverna é ele mesmo, e ele "convida" Odisseu e seus companheiros em seu altar a participar do banquete, não de acordo com a prática comum dos sacrifícios, mas como vítimas.

32 No original: "many scholars read Polyphemus' response to Odysseus as a caricature of contemporary anti-democratic ideology, associated with historical figures like Callicles or Thrasymachus. In particular, Polyphemus' worship of his belly and his dismissal of law are heard as echoes of the arguments in favor of hedonism and against law that Callicles articulates in Plato's Gorgias".

33 No original: "the gods themselves have no existence in nature, but are a product of human artifice, and vary in different places according to local conventions. Goodness is one thing in nature and another by nomos, and as for justice, nature knows nothing of it. Men are forever disputing about it and altering it, and every change is valid from the moment it is made, owing its existence to artificial conventions rather than to nature. It is by theories like these that agitators incite the young to irreligion and sedition, urging them to adopt the 'right life according to nature', by which they mean a life of selfish ambition instead of service to their fellow-men and to law". 
Em vez de compartilhar a carne do sacrifício, eles serão oferecidos ao Ciclope como carne sacrificial (KATSOURIS, 1997, p. 11) ${ }^{34}$.

A política do selvagem é então a negação das potencialidades políticas, é o isolamento, a primazia pelo prazer imediato, a tirania do estômago como único deus. É a negação dos parâmetros civilizacionais argumentados por Odisseu. Eurípides ampliou o status da selvageria de Polifemo para além do paradigma arcaico do homem selvagem e, ao mesmo tempo, reafirmou na figura de Odisseu os padrões civilizatórios gregos.

Considerações finais

Eurípides apropria-se do mito homérico de Odisseu e Polifemo, que guarda consigo os elementos de selvagem e civilizado, para estruturar uma nova significação no selvagem, um emblema político. Polifemo é selvagem à medida que ignora todas as características civilizatórias estabelecidas por Odisseu. Ao ser apresentado à visão de mundo de Odisseu, ele apresenta a própria e, além de negar todos os postulados, pretende ainda matá-lo e devorá-lo.

Em seu modo de vida, Polifemo é um referencial negativo daquilo que não pode ser seguido, da animalidade que irrompe ao ignorar os costumes, como a boa hospitalidade, $o$ respeito aos deuses e a política. O selvagem, na figura de Polifemo, serve como um grande argumento do que pode se tornar uma pólis em que os homens se esquecem da política e decidem somente agir em benefício de si mesmos. Polifemo deseja devorar o outro e, nessa lógica da anulação, a pólis ficaria sitiada por interesses que não o bem comum.

O drama satírico serve para demonstrar o perigo de uma cidade na qual todos se transformam em Polifemo. Sem respeito às leis, os homens se reduziriam ao seu estômago. Odisseu, apesar de não ser a figura mais virtuosa para o século V a.C., representa em suas virtudes o espírito da política ateniense que encontra um monstro de caráter hedonista. A peça de Eurípides pode ser vista como um microcosmo do debate nómos-phýsis.

Jean-François Mattéi, em um ensaio sobre a barbárie, defende que "a condição maior da barbárie de nosso tempo consiste na retirada do sujeito para sua interioridade" (MATTÉI, 2002, p. 12). A leitura do Ciclope pode indicar a nós modernos o perigo de esquecer a política para buscarmos somente nossos próprios interesses. Se durante muito tempo a astúcia de nossos feitos como civilização burguesa nos colocaram na figura de Odisseu como lembra a Dialética do esclarecimento (ADORNO; HORKHEIMER, 1985), agora temos que pensar se não fomos reduzidos a Polifemo: um mundo no qual a nossa interioridade é tão grande que somente buscamos a nós mesmos.

\section{Referências}

ADORNO, Theodor; HORKHEIMER, Max. Dialética do esclarecimento. Rio de Janeiro: Zahar Editores, 1985.

34 No original: "Polyphemus is the incarnation of both. It is typical that he begins and ends his speech with a reference to god. His last two lines do not leave any margin for doubt. The god of the cave is he himself and he 'invites' Odysseus and his companions at his altar to participate in the banquet, not in accordance with the usual practice at the sacrifices, but as victims. Instead of sharing the sacrificial meat, they will be offered as sacrificial meat to the Cyclops". 
ARISTÓTELES. Politique. Paris: Les Belles Lettres, 1991.

BARBOSA, T. V. R. Cabeça de homem, ventre de animal: sátiros, centauros e homens. In: JEHA, J.; NASCIMENTO, L. (orgs.). Da fabricação de monstros. Belo Horizonte: Editora UFMG, 2009, p. 24-39.

BLAMIRES, Harry. The new bloomsday book: a guide through Ulysses. London: Routledge, 1996.

BORGEAUD, Philippe. Le rustre (263-279). In: VERNANT, Jean-Pierre. L'homme grec. Paris: Éditions du Seuil, 1993.

BRANDÃO, Junito S. O ciclope. In: Teatro grego: Eurípides e Aristófanes, um drama satírico e duas comédias. Rio de Janeiro: Espaço e Tempo, 1987, p. 37-68. BRANDÃO, Vanessa Ribeiro. Uma tradução dramática do Ciclope de Eurípides. 2017. Tese (Doutorado em Literaturas Clássicas e Medievais) - Universidade Federal de Minas Gerais, Belo Horizonte, 2017.

BUFFIÈRE, Félix. Les mythes d'Homère et la pensée grecque. Paris: Les Belles Lettres, 1956.

CHANTRAINE, Pierre. Dictionnaire étymologique de la langue grecque. Paris: Klincksiek, 1999.

CHARPENTIER, Marie-Claude. Avant-propos. In: Les espaces du sauvage dans le monde antique: approches et définitions. Besançon: Institut des Sciences et Techniques de 1'Antiquité, 2004, p. 03-08.

. Les frontières du sauvage dans l'Antiquité. In: . Cahiers des études anciennes, 2015, p. 7-18.

DAGIOS, Mateus. Pólis enferma: Nósos e a representação do lógos sofístico nas tragédias Filoctetes de Sófocles e Orestes de Eurípides. 2019. Tese (Doutorado em História) - Universidade Federal do Rio Grande do Sul, Porto Alegre, 2019.

DOUGHERTY, Carol. The double vision of Euripides" "Cyclops": an ethnographic "Odyssey" on the satyr stage comparative drama. Comparative Drama, v. 33, n. 3, 1999, p. 313-338.

EASTERLING, P. E. Anachronism in Greek Tragedy. The Journal of Hellenic Studies, V. 105,1985 , p. 1-10.

EURÍPIDES. Ciclope. In: ___ . Teatro grego: Eurípides e Aristófanes, um drama satírico e duas comédias. Rio de Janeiro: Espaço e Tempo, 1987. Tradução de Junito S. Brandão.

GOULD, John. Hiketeia. The Journal of Hellenic Studies, v. 93, 1973, p. 74-103. GUTHRIE, W. K. C. The sophists. Cambridge: Cambridge University Press, 1971. HARTOG, F. O espelho de Heródoto. Belo Horizonte: Editora da UFMG, 1999. HOMERO. Odisseia. São Paulo: Penguin Classics/Companhia das Letras, 2011. Tradução de Frederico Lourenço.

KATSOURIS, A. G. Euripides' Cyclops and Homer's Odyssey: an interpretative comparison, Prometheus, XXIII, 1997, p. 01-25.

KONSTAN, D. An anthropology of Euripides' Cyclops. In: WINKLER, J. J.; ZEITLIN, F. I. (orgs.). Nothing to do with Dionysos? Athenian drama in its social context. Princeton: Princeton University Press, 1990, p. 87-103. . A amizade no mundo clássico. São Paulo: Odysseus, 2005. KOVACS, David. Euripides / Cyclops, Alcestis / Medea. Cambridge: Cambridge University Press, 2001. 
MATTÉI, Jean-François. A barbárie interior: ensaio sobre o i-mundo moderno. São Paulo: Unesp, 2002.

MAUDUIT, Christine. La sauvagerie dans la poésie grecque d'Homère à Eschyle. Paris: Les Belles Lettres, 2006.

MINOIS, George. História da solidão e dos solitários. São Paulo: Unesp, 2019. LOBATO, Monteiro. Aventuras de Hans Staden. São Paulo: Companhia Editora Nacional, 1927.

MONTIGLIO, Silvia. From villain to hero: Odysseus in ancient thought. Ann Arbor: University of Michigan Press, 2011.

O'SULLIVAN, Patrick. Dionysos, Polyphemos, and the idea of Sicily in Euripides' Cyclops. In: ROSENBLOOM, D.; DAVIDSON, J. (eds.). Greek drama IV: texts, contexts, performance. Oxford: Aris \& Phillips, 2012, p. 169-189.

O'SULLIVAN, P.; COLLARD, C. Euripides, cyclops and major fragments of Greek satyric drama. Oxford: Aris \& Phillips Classical Texts, 2013.

ROBERT, Louis. Recherches épigraphiques. Revue des Études Anciennes, v. 62, n. 3-4, 1960, p. 276-361.

RODRIGUES, Guilherme F. O ciclope de Eurípides: estudo e tradução. 2016.

Dissertação (Mestrado em Letras) - Universidade de São Paulo, São Paulo, 2016.

ROMILLY, Jacqueline de. Thucydide et l'idée de progrès. Lettere, Storia e Filosofia, série II, v. 35, n. 3-4, 1966, p. 143-191.

ROSENBLOOM, David. Staging rhetoric in Athens. In: GUNDERSON, Erik (ed.). The Cambridge Companion to Ancient rhetoric. Cambridge: CUP, 2009, p. 194-209.

SEAFORD, Richard. The date of Euripides' Cyclops. The Journal of Hellenic Studies, v. 102, 1982, p. 161-172.

SHAW, Carl A. Satyric play: the evolution of Greek Comedy and satyr drama. Oxford: Oxford University Press, 2014.

SMITH, William (ed.). Dictionary of Greek and Roman Antiquities. London: John Murray, 1870.

SOARES, Carmen L. Ciclope: introdução, tradução do grego e notas. In: SOUSA E SILVA, Maria de Fátima (coord.). Eurípides, Tragédias I. Lisboa: Imprensa Nacional Casa da Moeda, 2009.

SUTTON, D. F. The Greek satyr play. Meisenheim am Glan: Hain, 1980.

TORRANO, JAA. Eurípides: teatro completo I. São Paulo: Editora Iluminuras Ltda, 2015.

TURATO, Fabio. La crisi della città e l'ideologia del selvaggio nell'Atene del V secolo a.C. Roma: Edizioni dell'Ateneo \& Bizzarri, 1979.

VENEZIA, Luigi. La figura di Polifemo nel teatro greco: trasformazioni di un mostro. Pontremoli, Milano, n. 1, mar. 2007, p. 95-135.

VICKERS, Michael. Alcibiades on Stage: "Philoctetes" and "Cyclops". Historia:

Zeitschrift für Alte Geschichte, bd. 36, h. 2, 2nd qtr., 1987, p. 171-197.

WYNTER, Sylvia. "A different kind of creature": Caribbean literature, the Cyclops factor and the Second Poetics of the propter nos. In: REISS, Timothy J. (ed.). Sisyphus and Eldorado: magical and other Realisms in Caribbean literature. Trenton, NJ: Africa World, 2002, p. 143-67. 
ZANON, Camila. Onde vivem os monstros: criaturas prodigiosas na poesia hexamétrica arcaica. 2016. Tese (Doutorado em Letras Clássicas) - Universidade de São Paulo, São Paulo, 2016.

Recebido em: 30/05/2020; Aceito em: 14/06/2020. 